\title{
Extracellular vesicles small RNA clusters: hit the nail on the head of liver cancer detection
}

\author{
Artur Słomka ${ }^{1 \#}$, Bingduo Wang ${ }^{2 \#}$, Tudor Mocan ${ }^{3}$, Maria González-Carmona $^{2}$, Christian P. Strassburg ${ }^{2}$, \\ Veronika Lukacs-Kornek ${ }^{4}$, Miroslaw T. Kornek ${ }^{2}$
}

${ }^{1}$ Department of Pathophysiology, Nicolaus Copernicus University in Toruń, Ludwik Rydygier Collegium Medicum, Bydgoszcz, Poland; ${ }^{2}$ Department of Internal Medicine I, University Hospital of the Rheinische Friedrich-Wilhelms-University, Bonn, Germany; ${ }^{3}$ Octavian Fodor Institute for Gastroenterology and Hepatology, Iuliu Haţieganu, University of Medicine and Pharmacy, Cluj-Napoca, Romania; ${ }^{4}$ Institute of Experimental Immunology, University Hospital of the Rheinische Friedrich-Wilhelms-University, Bonn, Germany

\#These authors contributed equally to this work.

Correspondence to: Miroslaw T. Kornek, PhD. Department of Internal Medicine I, University Hospital of the Rheinische Friedrich-WilhelmsUniversity, 53127 Bonn, Germany. Email: miroslawkornek@web.de.

Comment on: von Felden J, Garcia-Lezana T, Dogra N, et al. Unannotated small RNA clusters associated with circulating extracellular vesicles detect early stage liver cancer. Gut 2021. [Epub ahead of print]. doi: 10.1136/gutjnl-2021-325036.

Submitted Oct 11, 2021. Accepted for publication Oct 25, 2021.

doi: $10.21037 / \mathrm{hbsn}-21-421$

View this article at: https://dx.doi.org/10.21037/hbsn-21-421

There is a very urgent need and clinical demand of robust biomarkers in cancer screening, especially in early hepatocellular carcinoma (HCC) surveillance as outlined by various professional international associations as the European Association for the study of the Liver (EASL), or the Asian Pacific Association for the Study of the Liver (APASL) and national professional organisations as the American Association for the Study of Liver Diseases (AASLD), besides others. Newest data on primarily HCC is still depicting this cancer entity as the sixth most frequently diagnosed cancer, with over 900,000 new cases and over 830,000 deaths worldwide (1). This type of cancer, therefore, remains at the forefront of malignant diseases. Thus, every element of patient management, including early diagnosis and prognosis of treatment response and survival, is a challenge.

Now, hepatic cancer screening, allowing a tight HCC surveillance in patients at risk, could increase HCC early detection rates manifold. Hepatic cancer-detecting, especially early HCC diagnosis, could be part of a comprehensive, personalized medicine approach combined with a convenient and patient-friendly liquid biopsy approach such as published by us and others (2-5). The term 'liquid biopsy' actually means the possibility of assessing various types of cancer biomarkers in readily available biological material, mainly peripheral blood, using a variety of laboratory methods. This technique is devoid of most of the side effects of standard tumour biopsy, is less invasive to the patient, and can be performed multiple times. Nevertheless, the lack of standardization of laboratory methods or the liquid version's high procedural and apparatus costs prohibit it from replacing the standard biopsy. The use of liquid biopsy and its undoubted advantages, e.g., drawing just a few millilitres of blood, would allow physicians and oncologists around the globe to render an earlier picture of the underlying hepatic malignancy, achieving a better individual outcome with a more prominent likelihood of reaching a fair 5-year survivable probability. Currently, the reported overall survival (OS) rates are for primary liver cancer overall low as $21.3 \%$ during 2000-2011 (5-year) and 58.1\% during 2000-2015 (1-year) in the United States (US), both have been improved over the past decades (6).

Previously, many experimental and clinical studies on liquid biopsies in liver cancer were done, however, only few of those will result or initiated a phase 2 biomarker case-control study by FDA standards. July this year, the GUT published the original research results of von Felden et al. (7), in which the authors elegantly demonstrated that the use of small RNA clusters associated with blood extracellular vesicles (EVs) is an excellent 


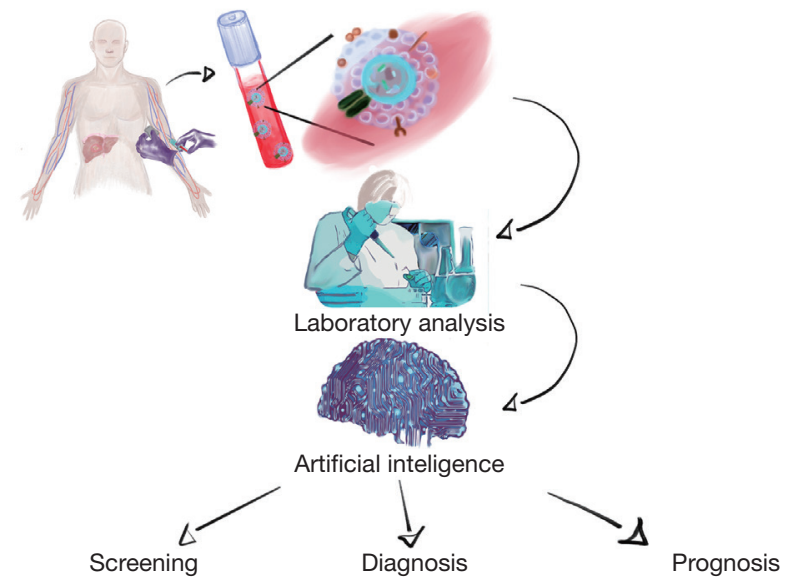

Figure 1 A simplified concept of the use of liquid biopsy in clinical oncology proposed by von Felden et al. (7). Thanks to innovative laboratory methods and IT technologies, it is possible to accurately and sensitively screen and diagnose liver cancers and assess their progression. Evaluation of EVs in readily available samples of biological material and analysis of results with AI can become part of personalized medicine, and replace the standard solid biopsy. EVs, extracellular vesicles; AI, artificial intelligence.

type of liquid biopsy, allowing HCC detection with very high sensitivity and specificity. So, what are EVs? EVs are membranous structures released from cells due to various biological processes, e.g., activation, inflammation and apoptosis. These structures are currently believed to include exosomes, ectosomes as microparticles (MPs), microvesicles (MVs) and apoptotic bodies. EVs display a variety of biologically active molecules on their surface, making them universal transmitters of information from cell to cell (8). Naturally, the manuscript of von Felden et al. (7) is not the only one showing the utility of EVs for diagnosing HCC. Previously, the main scientific focus was devoted to various forms of RNA associated with exosomes. However, this work by von Felden is unique, as it covers several experiments and has been validated in a phase 2 biomarker case-control study.

Importantly, von Felden et al. (7) demonstrated beautifully how current machine learning (ML), kind of artificial intelligence (AI), when ML driven modelling is pitching in Figure 1, ultimately allows us to exploit extensive data and analyse and identify complex patterns/ profiles of various until now uncharacterized unannotated small RNAs, typical of a consensus sequence of $20 \mathrm{nt}$. Data management and data mining are crucial in AI-based future comprehensive cancer screening.

In our opinion, the work done by von Felden et al. (7) does fulfil the criteria to make a difference in the near future, a significant contribution in the desperate search for robust liquid biopsy biomarkers in HCC and might set a new medical standard in clinical oncology. The so far reported sensitivity and specificity of $86 \%$ and $91 \%$, respectively, for the detection of early HCC from controls at risk to develop HCC as hepatic cirrhosis, is promising and much better then widely used alpha-fetoprotein (AFP), or carcinoembryonic antigen (CEA). Nevertheless, the final and complete report analysis of phase 2 biomarker casecontrol study by FDA standards will set the pace. Their key finding as that a certain so called 3-smRC signature allowed such separation of hepatic malignancy from nonmalignant cirrhosis that is in fact a related pathological process in HCC development is remarkable and has similar value as the publication by Melo et al. (9) reporting that GPC1+ small EVs are highly beneficial in pancreatic cancer screening and kicking off many further exploitations. However, being enthusiastic about von Felden's publication, at the same time we have to be as much critical as enthusiastic and address some critical but necessary and fair questions such as: does their 3-smRC signature allow a separation between other cancer entities? Especially, does their 3-smRC signature allow a clear separation between HCC and intrahepatic CCA? Others tried this, even utilising circulating EVs as a novel biomarker $(4,5,10)$. However, those questions remained unanswered yet. Probably, addressed in a future publication by von Felden and colleagues or others. Moreover, a relatively small number of patients and controls make us treat these results as preliminary. For the moment, this work as published in Gut is very promising and deserves visibility and further discussion.

\section{Acknowledgments}

Funding: This publication was funded by the Deutsche Forschungsgemeinschaft (DFG; German Research Foundation), grant number 410853455 to MTK and grant number 411345524 to VLK. We are remarkably grateful to Wioleta Chomko for assistance with the figure.

\section{Footnote}

Provenance and Peer Review: This article was commissioned by the editorial office of Hepatobiliary Surgery and Nutrition. 
The article did not undergo external peer review.

Conflicts of Interest: All authors have completed the ICMJE uniform disclosure form (available at https://hbsn. amegroups.com/article/view/10.21037/hbsn-21-421/coif). VLK and MTK report grant from DFG, German Research Foundation. The other authors have no conflicts of interest to declare.

Ethical Statement: The authors are accountable for all aspects of the work in ensuring that questions related to the accuracy or integrity of any part of the work are appropriately investigated and resolved.

Open Access Statement: This is an Open Access article distributed in accordance with the Creative Commons Attribution-NonCommercial-NoDerivs 4.0 International License (CC BY-NC-ND 4.0), which permits the noncommercial replication and distribution of the article with the strict proviso that no changes or edits are made and the original work is properly cited (including links to both the formal publication through the relevant DOI and the license). See: https://creativecommons.org/licenses/by-nc-nd/4.0/.

\section{References}

1. Sung H, Ferlay J, Siegel RL, et al. Global Cancer Statistics 2020: GLOBOCAN Estimates of Incidence and Mortality Worldwide for 36 Cancers in 185 Countries. CA Cancer J Clin 2021;71:209-49.

2. Mocan T, Simão AL, Castro RE, et al. Liquid Biopsies in Hepatocellular Carcinoma: Are We Winning? J Clin Med

Cite this article as: Słomka A, Wang B, Mocan T, González-Carmona M, Strassburg CP, Lukacs-Kornek V, Kornek MT. Extracellular vesicles small RNA clusters: hit the nail on the head of liver cancer detection. HepatoBiliary Surg Nutr 2022;11(1):100-102. doi: 10.21037/hbsn-21-421
2020;9:1541.

3. Urban SK, Mocan T, Sänger H, et al. Extracellular Vesicles in Liver Diseases: Diagnostic, Prognostic, and Therapeutic Application. Semin Liver Dis 2019;39:70-7.

4. Julich-Haertel H, Urban SK, Krawczyk M, et al. Cancerassociated circulating large extracellular vesicles in cholangiocarcinoma and hepatocellular carcinoma. J Hepatol 2017;67:282-92.

5. Urban SK, Sänger H, Krawczyk M, et al. Synergistic effects of extracellular vesicle phenotyping and AFP in hepatobiliary cancer differentiation. Liver Int 2020;40:3103-16.

6. Lee YT, Wang JJ, Luu M, et al. The Mortality and Overall Survival Trends of Primary Liver Cancer in the United States. J Natl Cancer Inst 2021. [Epub ahead of print]. doi: 10.1093/jnci/djab079.

7. von Felden J, Garcia-Lezana T, Dogra N, et al. Unannotated small RNA clusters associated with circulating extracellular vesicles detect early stage liver cancer. Gut 2021. [Epub ahead of print]. doi: 10.1136/ gutjnl-2021-325036.

8. Mathieu M, Martin-Jaular L, Lavieu G, et al. Specificities of secretion and uptake of exosomes and other extracellular vesicles for cell-to-cell communication. Nat Cell Biol 2019;21:9-17.

9. Melo SA, Luecke LB, Kahlert C, et al. Glypican-1 identifies cancer exosomes and detects early pancreatic cancer. Nature 2015;523:177-82.

10. Banales JM, Iñarrairaegui $M$, Arbelaiz $A$, et al. Serum Metabolites as Diagnostic Biomarkers for Cholangiocarcinoma, Hepatocellular Carcinoma, and Primary Sclerosing Cholangitis. Hepatology 2019;70:547-62. 